\title{
Design and Development of Manual Hank Reeling Machine
}

\author{
Mr. Fitsum Etefa Ahmed \\ Lecturer (Msc. in Leather product Design and Engineering) \\ BSc. in Textile Engineering \\ Leather Engineering Department \\ Ethiopian Institute of Textile and Fashion Technology (EiTEX) \\ Bahir Dar University, Bahir Dar, Ethiopia
}

\begin{abstract}
In today's Textile product processing, customers are demanding lower prices, the best quality product and service. An effective cost reduction and higher productivity with short processing time is the main objective for textile manufacturer to be a strong competitor by having high market share with profitability and to compete successfully in the world market by keeping benefits of stoke holders including customers.

Nowadays there is different manual and automatic hank reeling machine. Hank reeling machine used to reel cone yarn to hank yarn form. Automatic hank reeling machine works by use of electric power system and has motor for Hank reeling. This machine can wind a maximum number of hanks within one reeling cycle of machine. It's less time consuming, but expensive.

Hand hank reeling machine can wind single hank per reeling cycle and its time consuming than automatic reeling machine. Based on data analysis, the researcher designed and fabricated manual hank reeling machine which can be driven easily by using foot. This machine can wind up to 12 hanks within single hank reeling cycle.
\end{abstract}

Keywords: Yarn; hank yarn; hank reeling; cone yarn; weaving; knitting

\section{INTRODUCTION}

The interest of producing textile and related product are increasing in the world. The abundance in nature combined with the ease of Textile processing was an attractive feature, which makes it an important income for the development of a given country. Nowadays different latest textile machineries are developed by different manufacturers. In production of Yarn, the main input fiber is changed into yarn by passing through different yarn production sequence. Winding is one of the most important operation, which is mainly occurred in spinning section. In fabric manufacturing, winding as well as rewinding is so important. The creation of large yarn packages that can be easily wounded and unwound, is called winding [1-7].

In textile industry, a hank is a coiled or wrapped unit of yarn. This is often the best form for use with handlooms, compared to the cone form needed for powerlooms. Hanks come in varying lengths depending on the type of material and the manufacturer [8-9]. For instance, a hank of linen is often 300 yards $(270 \mathrm{~m})$, and a hank of cotton or silk is 840 yards $(770 \mathrm{~m})$. While hanks may differ by manufacturer and by product, a skein is usually considered $1 / 6$ th of a hank (either by weight or by length) [8-11].
In yarns for handcrafts such as knitting or crochet, hanks are not a fixed length but are sold in units by weight, most commonly 50 grams. Depending on the thickness of the strand as well as the inherent density of the material, hanks can range widely in yardage per 50 gram unit. Knitters and crocheters rewind the hanks into balls or centre-pull skeins prior to use, in order to prevent the yarn from becoming tangled. Hank reeling machine is used to change cone or cop packed yarn into a hank form by winding a yarn into a circular or round shaped reel. To produce these fabrics, hank is used as main input. [8-10]. Automatic hank reeling machine works by use of electric power system and has motor for hank reeling. This machine can wind a maximum number of hanks within one reeling cycle of machine. It's less time consuming, but expensive [12-18].

In Ethiopia, Textile product manufacturing is one of a key sector that identified by the government since 2010. The Ethiopia industrialization strategy has given top priority to textile product processing. The several opportunity and suitability of the general atmosphere for the growth of textile industries in the country some local and foreign investors are investing their knowledge and capital in textile industry. In Ethiopia there are large number of small scale knitted and woven fabric producers. To produce these fabrics the main input they using is hank yarn [19-22].

Local knitted and woven fabric producers can purchase a cop packed yarn from market and they change into hank form by using small manual hand driven hank reeling machine. However, the amount of hank produced by manual reeling machine does not satisfy the need of small scale knitted and woven fabric producers and it leads to very high hank cost. Therefore, this problem was a notable hindrance limiting the industrial growth of the country. The present work aims at fabricating a manual reeling machine that can be operated easily, with less manufacturing cost, rotates by using foot and capable of winding more number of hanks per cycle [23-26].

Materials

\section{METHODOLOGY}

Hollow Structural Sections of circular (CHS) pipe, Rectangular (RHS), Tubular steel, Sheet Metal, Bearing, pulley, Worm Gear etc., were used in fabrication work. 


\section{Methods}

There are various types of hank reeling machine available in the different textile industries. Different researchers have been done on modification of Automatic hank reeling machine [27-32]. These machines are particularly fully automated and of high cost, which are not purchasable to the Small scale enterprises. This indicates that manual hank reeling machine requires modification.

The main aim of designing and fabricating a manual hank reeling machine which winds more hank per reeling cycle, was achieved by changing some mechanism of hand reeling machine. In manual hank reeling the operator uses his hand to wind hank yarn and can wind single hank per cycle. This is now changed in the present design by changing the driving unit from hand to foot and by extending the width of reel in order to wind up to 12 hanks per reeling cycle. This allows comfort for the operator, because the operator got a possibility to drive the reel by his foot like fabric sewing machine, by sitting on a chair.

Design of Manual Hank reeling machine parts

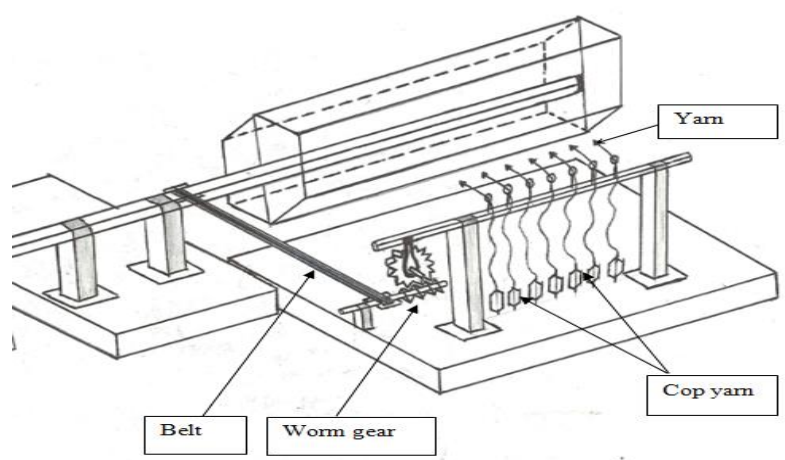

Figure 1. Manual Hank reeling Machine design

As indicated in Figure 1, the reeling part used to wind hank yarn and worm gear and worm shafts are used to push yarn traverse rod. Yarn traverse used to distribute the yarn uniformly throughout the width of hank.

Table 1. Manual Hank reeling Machine specification

\begin{tabular}{|l|l|l|l|}
\hline S.No. & Machine parts & Dimension & Material Type \\
\hline 1 & Reel Length & $\begin{array}{l}\text { Reel Length } 90 \mathrm{~cm}, \text { Reel Circumference } \\
80 \mathrm{~cm}\end{array}$ & $10 \mathrm{~mm}$ Round bar \\
\hline 2 & Reel support & Length $50 \mathrm{~cm}$ & Hollow Structural Sections of circular (CHS) pipe 50*2 \\
\hline 3 & Yarn Traverse support & Length $65 \mathrm{~cm}$ & CHS Pipe $25 * 1.25$ \\
\hline 4 & Yarn Traverse & Length $110 \mathrm{~cm}$ & $10 \mathrm{~mm}$ Round bar \\
\hline 5 & Reel Frame & $60 \mathrm{~cm} * 40 \mathrm{~cm}$ & RHS Tubular steel \\
\hline 6 & Feeding frame & $110 \mathrm{~cm} * 60 \mathrm{~cm}$ & RHS Tubular steel \\
\hline 7 & Shaft & Length $160 \mathrm{~cm}$ & Hollow Structural Sections of circular (CHS) pipe $25^{*} 1.25$ \\
\hline 8 & Ball Bearing & $25 * 52$ & - \\
\hline 9 & Worm Gear & 100 Teeth number & - \\
\hline 10 & Sheet Metal & $1.25 \mathrm{~mm}$ Thickness & - \\
\hline
\end{tabular}

As shown in Table 1, the machine has a $160 \mathrm{~cm}$ long $25 * 1.25$ Hollow Structural Sections of circular (CHS) pipe main shaft, on which $20 \mathrm{~cm}$ length 6 round bars are welded at one end of the shaft and $20 \mathrm{~cm}$ length 6 round bars are welded at $90 \mathrm{~cm}$ end of the shaft in opposite direction. A $90 \mathrm{~cm}$ Length 6 round bar reel parts are welded with $20 \mathrm{~cm}$ Length round bars in both edge of reel parts.

The main shaft is supported by two $50 \mathrm{~cm}$ long $50 * 2$ Hollow Structural Sections of circular (CHS) pipe vertically welded on machine frame with having two $25 * 52$ ball Bearing and Bearing house at the edge of shaft support. The one edge of main shaft is welded with the driving unit Pit man rod and foot treadle part which is taken from fabric sewing machine. When the foot treadle driving unit rotates, the reel which is fixed on the shaft starts reeling the cone or cop yarn into the reel and forms a hank yarn.

The machine has a feeding unit to feed cone or cop packed yarn to the reeling unit. There is $110 \mathrm{~cm}$ long yarn traverse round bar used to distribute the yarn throughout the hank width. The machine has worm gear with 100 teeth number. The worm gear is connected with main shaft by belt. A small length rod is welded on the worm gear there is a 
small length rod. In yarn traverse rod a small key like tongue is connected. During reeling, when the shaft rotates one cycle, one of the worm gear teeth forward and a small rod on the worm gear pushes the key like tongue welded on yarn traverse rod. Yarn feed welded on yarn feed Yarn traverse distribute the hank yarn uniformly throughout the width of hank. A $1.25 \mathrm{~mm}$ Thickness sheet metal is welded on machine frame in order to hold yarn cones and cops.

\section{RESULT AND DISCUSSION}

Table 2: Fabricated manual hank reeling machine description

\begin{tabular}{|l|l|l|}
\hline S.No & Description & Description \\
\hline 1 & Type of machine & Manual hank reeling machine \\
\hline 2 & Number of hank produced per cycle & 12 \\
\hline 3 & Working condition & Manual \\
\hline 4 & Required Number of operator & Single \\
\hline 5 & Spinning method & Winding \\
\hline 6 & Material input & Cone or cop packed yarn \\
\hline 7 & Material output & Hank yarn \\
\hline 8 & Maintenance system used & Oiling and cleaning \\
\hline 9 & Swift circumference & 1.2 meter \\
\hline 10 & Length of machine & 1.8 meter \\
\hline 11 & Width of machine & 1.1 meter \\
\hline 12 & Height of machine & 1 meter \\
\hline
\end{tabular}

Table 2 shows, fabricated manual hank reeling machine description. The machine has 1.8 meter length, 1.1 meter width and 1 meter height. It used to convert cone or cope yarn to hank yarn. It requires one operator and requires simple maintenance. It can wind 12 hanks with one reeling cycle.
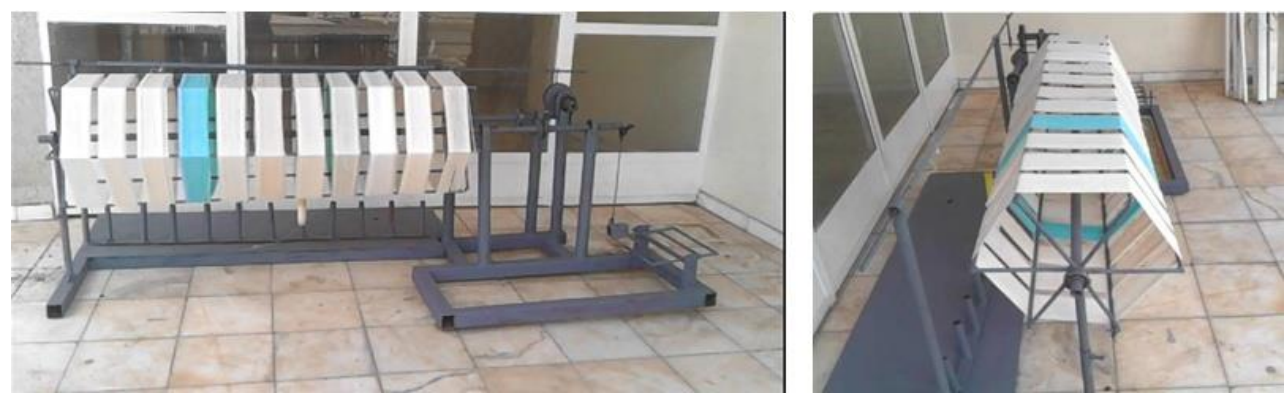

Figure 2. Front and Side view of fabricated manual hank reeling machine

As indicated in Figure 2, fabricated manual hank reeling machine can be driven easily by foot like sewing machine treadle. The machine has 80 circumference reels. In one rotation, the reel can wind $80 \mathrm{~cm}$ hank. The author recorded reel rotation of 5 people in minutes. Each person rotates 10 times and the average reel rotation is $120 \mathrm{rpm}$ (revolution per minutes). Machine can wind 96 meters in a minutes. The Length of one hank of cotton is $760 \mathrm{~m}$ and machine wind full hank within 7.91 minutes per reeling cycle. The new fabricated Manual hank reeling machine can reel 12 hanks within one reeling cycle or within 7.91 minutes. The produced hank yarn is distributed uniformly throughout the width of hank. The cost to fabricate this machine is very cheap compared to Automatic Electrical hank reeling machine. To fabricate this machine, it costs only around $530 \$$ as compared to $4000 \$$ in case of an Automatic Electrical hank reeling machine.

\section{CONCLUSION}

In Ethiopia, Textile sector plays a very important role in the Economic growth of the Country. Different domestic and foreign companies are investing their capital in this sector. In the country there are a large number of Small scale enterprises working in producing woven and knitted related fabrics. Most of the enterprises use a hank yarn to produce a woven fabric. To convert Cone yarn to hank yarn, they use hand driven manual single hank reeling machine. This machine is tedious and less productive. The aim to design manual foot driven hank reeling winding machine is that to reduce the time for the reeling of hank. The job of reeling single hank is very tiresome. Also the time required for the reeling hank varies largely from worker to worker, thus making process is time unpredictable. This work lead to develop easily controlled manual hank reeling machine. This will make hank reeling process convenient for woven fabric production. It is proposed to fabricate the hank reeling machine to distribute 
to the small scale woven fabric producers in this part of the country.

Data availability: All data used for the current study available online.

Competing interests: The author declare that there is no competing interest.

\section{ACKNOWLEDGEMENT}

The Author wishes to express his sincere thanks to Ethiopian Institute of Textile and Fashion Technology, Bahir Dar University for the support in successful completion of the work.

\section{REFERENCES}

[1] Marie C. Ultimate A to Z Companion to 1,001 Needle craft Terms: Applique, Crochet, Embroidery, Knitting, Quilting, Sewing and More. Publisher: St. Martin's, New York, United States. ISBN-10: 0312377770, 2007.

[2] Stuart, Hunter Archibald. "Manufacture of textile yarn." U.S. Patent No. 2,328,074. 31 Aug. 1943.

[3] Barrett, Homer D., Robert T. Estes, and Jr George C. Stow. "Yarn manufacture and products obtained thereby." U.S. Patent No. 3,113,369. 10 Dec. 1963.

[4] Tabata, Masaaki, et al. "Spinning method and apparatus for manufacturing yarn from textile fibers." U.S. Patent No. 3,523,300. 4 Aug. 1970.

[5] Birrell, Verla. "The textile arts." (1959).

[6] Adanur, Sabit. Handbook of weaving. CRC press, 2000.

[7] Marks, R. and Robinson, A.T.C., 1976. Principles of weaving (pp. 249-249)

[8] Tavanai, H., M. J. Denton, and J. G. Tomka. "Direct objective measurement of yarn-torque level." Journal of the Textile Institute 87.1 (1996): 50-58.

[9] Heinrich, Buddecke. "Method and means for reeling of yarn." U.S. Patent No. 2,889,610. 9 Jun. 1959.

[10] Dorothy T. Knitting Know-How. Krause publications 2012; p. 11.ISBN9781440218194.

[11] Misao J. My hand-weaving SAORI. Available at http://www.rehab.go.jp/english/whoclbc/pdf/E28.pdf. Osaka, Japan, 1995.

[12] Chiyuki O. SAORI Small Step by - Consideration on the small steps in learning the weaving process and the process of creating teaching materials - with CD-ROM. 2004; Kashimura Printing Co. Ltd. , P.14

[13] Milind K. Fundamentals of yarn winding. 2016; Published by Woodhead Publishing India Pvt. Ltd.

[14] Fabtex E. Fabtex Auto Reeling Machine. 2019; 240/7; Irugur Rd, available at www.fabtexbaler.com

[15] Zhejiang W. Hank Winding Machine WSF618A-01 Precise Winder. 2019; Zhejiang Wanshifa Textile Machinery CO.,Ltd http://www.wsf-tex.com/

[16] Akash S, Pramod G, Sagar P, Manish G. Design and Manufacturing of Silk Winding Machine. 2017; Volume: 04 Issue: International Research Journal of Engineering and Technology (IRJET).

[17] Chellamani K, Chattopadhyay D. Yarn quality improvement with an air jet attachment in cone winding. Indian journal of fiber \& textile research vol.25 December 2000; PP.289-294

[18] Bhandari V. Tata Mc. Design of Machine Elements. Edition II 2007.

[19] Kalaikathir A. Design Data Book. PSG College of Technology; Edition III May 2013.

[20] Alhayat Ge, Ömer F. The Art of Hand Weaving Textiles and Crafting on Socio-Cultural Values in Ethiopian (Review). 2018; Volume 5, Issue 12; International Journal of Advanced Multidisciplinary Research.
[21] Itagaki J. Gender-Based Textile-Weaving Techniques of the Amhara in Northern Ethiopia. Center for African Area Studies, Kyoto University, 2013

[22] Henze M. Tablet-Woven Curtains from Ethiopia. The Textile Museum Journal 2000; 85-100.

[23] Kanehisa, Keiichiro. "Woven or knit fabrics manufactured using yarn dyed raw silk." U.S. Patent No. 6,080,689. 27 Jun. 2000.

[24] Gervers M. Cotton and Cotton Weaving in Meroitic Nubia and Medieval Ethiopia. Textile History 1990; 21:13-30.

[25] Staritz, Cornelia, and Lindsay Whitfield. Made in Ethiopia: the emergence and evolution of the Ethiopian apparel export sector. CAE Working Paper 2017: 3, Center of African Economies, Roskilde University, Roskilde, DK). Available at https://typo3. ruc. dk/fileadmin/assets/isg/02_Forskning/CAE/CAE_WP3_Staritz_a nd_Whitfield. pdf, 2017.

[26] Abdella, Aisha. "Assessment of Challenges, Opportunities and Prospects of Textile Industry in Ethiopia: The Case of Yirgalem Addis Textile Factory PLC." (2016)

[27] Yamazaki, S. "Hank reeling machine." U.S. Patent No. 3,825,196. 23 Jul. 1974

[28] Tanno, Naoichiro. "Automatic reeling machine." U.S. Patent No. 3,656,215. 18 Apr. 1972

[29] Delerue, Dominique M. "Reeling machine for forming a hank." U.S. Patent No. 4,185,790. 29 Jan. 1980

[30] Koichiro, Kubo, and Murata Yojiro. "Automatic reeling machine." U.S. Patent No. 3,408,714. 5 Nov. 1968.

[31] Kanehisa, Keiichiro. "Woven or knit fabrics manufactured using yarn dyed raw silk." U.S. Patent No. 6,080,689. 27 Jun. 2000.

[32] Fehrer, Ernst. "Apparatus for manufacturing a yarn." U.S. Patent No. 4,249,368. 10 Feb. 1981 